\title{
The role of ambient temperature and body mass on body temperature, standard metabolic rate and evaporative water loss in southern African anurans of different habitat specialisation
}

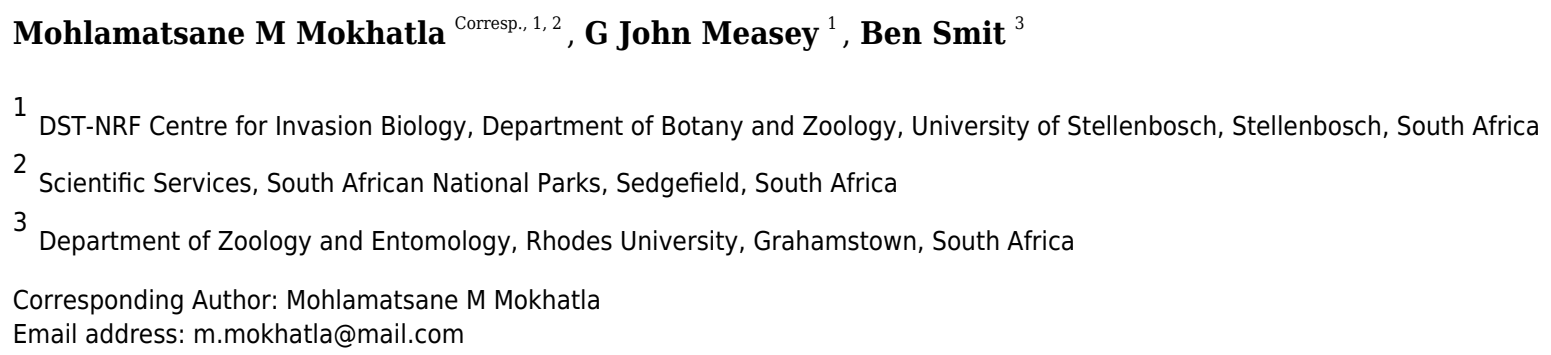

Temperature and water availability are two of the most important variables affecting all aspects of an anuran's key physiological processes such as body temperature $\left(T_{\mathrm{b}}\right)$, evaporative water loss (EWL) and standard metabolic rate (SMR). Since anurans display pronounced sexual dimorphism, evidence suggest that these processes are further influenced by other factors such as vapour pressure deficit (VPD), sex and body mass $\left(M_{\mathrm{b}}\right)$. However, a limited number of studies have tested the generality of these results across a wide range of ecologically relevant ambient temperatures $\left(T_{\mathrm{a}}\right)$, while taking habitat use into account. Thus, the aim of this study was to investigate the role of $T_{\mathrm{a}}$ on $T_{\mathrm{b}}$, wholeanimal EWL and whole-animal SMR in three species of wild caught African anuran species with different ecological specialisations: the principally aquatic African clawed frog (Xenopus laevis), stream-breeding common river frog (Amietia delalandii), and the largely terrestrial raucous toad (Sclerophrys capensis). Experiments were conducted at a range of test temperatures $\left(5^{\circ}-35^{\circ} \mathrm{C}\right.$, at $5^{\circ} \mathrm{C}$ increments). We found that VPD better predicted rates of EWL than $T_{\mathrm{a}}$ in two of the three species considered. Moreover, we found that $T_{\mathrm{b}}$, wholeanimal EWL and whole-animal SMR increased with increasing $T_{\mathrm{a}}$, while $T_{\mathrm{b}}$ increased with increasing $M_{\mathrm{b}}$ in $A$. delalandii and $S$. capensis but not in $X$. laevis. Whole-animal SMR increased with increasing $M_{\mathrm{b}}$ in $S$. capensis only. We did not find any significant effect of VPD, $M_{\mathrm{b}}$ or sex on whole-animal EWL within species. Lastly, $M_{\mathrm{b}}$ did not influence $T_{\mathrm{b}}$, wholeanimal SMR and EWL in the primary aquatic $X$. laevis. These results suggest that $M_{\mathrm{b}}$ may not have the same effect on key physiological variables, and that the influence of $M_{b}$ may also depend on the species ecological specialisation. Thus, the generality of $M_{b}$ as an 
important factor should be taken in the context of both physiology and species habitat specialisation. 
1 The role of ambient temperature and body mass on body temperature, standard metabolic

2 rate and evaporative water loss in southern African anurans of different habitat 3 specialisation

4

5 Mohlamatsane M. Mokhatla ${ }^{1,2}$, John Measey ${ }^{1} \&$ Ben Smit ${ }^{3}$

6

$7{ }^{1}$ Centre for Invasion Biology, Department of Botany and Zoology, Stellenbosch University, 7602,

8 South Africa

$9 \quad{ }^{2}$ Rondevlei Scientific Services, Garden Route National Park, South African National Parks, PO

10 Box 176, Sedgefield 6572, South Africa

$11{ }^{3}$ Department of Zoology and Entomology, Faculty of Science, Rhodes University, Grahamstown

12 6139, South Africa

13

14 Corresponding author

15 Mohlamatsane M. Mokhatla ${ }^{3}$ 


\section{Abstract}

18 Temperature and water availability are two of the most important variables affecting all aspects of an anuran's key physiological processes such as body temperature $\left(T_{\mathrm{b}}\right)$, evaporative water loss (EWL) and standard metabolic rate (SMR). Since anurans display pronounced sexual dimorphism, evidence suggest that these processes are further influenced by other factors such as vapour pressure deficit (VPD), sex and body mass $\left(M_{\mathrm{b}}\right)$. However, a limited number of studies have tested the generality of these results across a wide range of ecologically relevant ambient temperatures $\left(T_{\mathrm{a}}\right)$, while taking habitat use into account. Thus, the aim of this study was to investigate the role of $T_{\mathrm{a}}$ on $T_{\mathrm{b}}$, whole-animal EWL and whole-animal SMR in three species of wild caught African anuran species with different ecological specialisations: the principally aquatic African clawed frog (Xenopus laevis), stream-breeding common river frog (Amietia delalandii), and the largely terrestrial raucous toad (Sclerophrys capensis). Experiments were conducted at a range of test temperatures $\left(5^{\circ}-35^{\circ} \mathrm{C}\right.$, at $5^{\circ} \mathrm{C}$ increments $)$. We found that VPD better predicted rates of EWL than $T_{\mathrm{a}}$ in two of the three species considered. Moreover, we found that $T_{\mathrm{b}}$, whole-animal EWL and whole-animal SMR increased with increasing $T_{\mathrm{a}}$, while $T_{\mathrm{b}}$ increased with increasing $M_{\mathrm{b}}$ in $A$. delalandii and $S$. capensis but not in $X$. laevis. Whole-animal SMR increased with increasing $M_{\mathrm{b}}$ in $S$. capensis only. We did not find any significant effect of VPD, $M_{\mathrm{b}}$ or sex on whole-animal EWL within species. Lastly, $M_{\mathrm{b}}$ did not influence $T_{\mathrm{b}}$, whole-animal SMR and EWL in the primary aquatic $X$. laevis. These results suggest that $M_{\mathrm{b}}$ may not have the same effect on key physiological variables, and this may also depend on the species ecological specialisation. Thus, the generality of $M_{\mathrm{b}}$ as an important factor should be taken in the context of both physiology and species habitat specialisation. 


\section{Introduction}

Water and temperature are the two most important ecological determinants of species distribution patterns (Buckley \& Jetz, 2007; Qian et al., 2007; Riddell et al., 2017) through their influence on environmental energy availability (Currie, 1991; Chown et al., 2003). At a landscape level, they influence species abundance as well as activity patterns (Dabés et al., 2012; Peterman \& Semlitsch, 2014). At the physiological level, animals constantly need to maintain a positive energy and water balance in order to meet their short and long-term energy requirements for growth, development and reproduction (McNab, 2002). In contrast to endotherms (most birds and mammals; see Geiser, 1998), regulation of body temperature $\left(T_{\mathrm{b}}\right)$ of ectotherms is external and has been found to be highly correlated with ambient temperature $\left(T_{\mathrm{a}}\right.$ : Brattstorm, 1979; Huey, 1991; Angilletta, Niewiarowski \& Navas, 2002). In vertebrate ectotherms (fish, amphibians and reptiles), the regulation of $T_{\mathrm{b}}$ is maintained largely through behavioural means by selecting suitable microclimates (Lillywhite, 1970; Brattstrom, 1979; Wilson et al., 2000; Seebacher \& Alford, 2002; Köhler et al., 2011; Herrel \& Bonneaud, 2012; Herrel et al., 2014). Thus, given the diverse array of life-history traits within anurans and associated microclimates we might expect a variation in experienced $T_{\mathrm{b}}$, even within the same biogeographic setting.

\section{The maintenance of optimal $T_{\mathrm{b}}$, through the selection of suitable microclimate sites, determines} how ectotherms interact with their environment. Subsequently, several processes vital for survival such as food assimilation rates, performance and ultimately fitness, are all temperature dependent (Huey \& Stevenson, 1979; Huey \& Kingsolver, 1989; Angilletta, 2001; Angilletta et al., 2002; Seebacher \& Franklin, 2005; Buckley et al., 2012). Furthermore, $T_{\mathrm{b}}$ is crucial in determining key physiological processes such as evaporative water loss (EWL) and standard metabolic rates (SMR) in vertebrates (Huey, 1991); such that both EWL and SMR increase with an increase in temperature 
63 (Gillooly et al., 2001). This is mainly because higher temperatures generally increase enzyme

64 reaction rates (Gillooly et al., 2001; Brown et al., 2004).

65 These coupled increases in SMR and EWL are known to be influenced by body mass $\left(M_{\mathrm{b}}\right)$ such

66 that large bodied individuals have relatively low mass-specific rates (Gillooly et al., 2001) of

67 metabolism and water loss, irrespective of taxon (Tracy et al., 2010). Moreover, rate of heat loss

68 and gains depend on $M_{\mathrm{b}}$ in anurans (Carey, 1978). In addition to the role of $M_{\mathrm{b}}$ in determining rates

69 of EWL and SMR, several studies suggest that habitat use of an organism can drive EWL

70 requirements (Thorson, 1955). Evaporative water loss is particularly pronounced in amphibians

71 because most have moist, highly permeable skin (Spotila \& Berman, 1976; Shoemaker \& Nagy,

72 1977). Indeed, most amphibians lack physiological adaptations to regulate water loss; thus

73 suggesting that the rate at which some amphibians lose water is similar to an open water-body of

74 a similar size (Spotila \& Berman, 1976; Wygoda, 1984; Tracy et al., 2007 although see Dohm et

75 al., 2001; Burggren \& Vitalis, 2005).

Evidence suggests that amphibians occupying different ecological niches show pronounced differences in rates of EWL with arboreal frogs showing comparatively reduced rates of cutaneous water loss compared to non-arboreal groups (e.g. terrestrial and aquatic groups: Wygoda, 1984; Wygoda \& Garman, 1993; Young et al., 2005; Young et al., 2006). In some instances, anurans achieve this by covering their bodies with a water resistant waxy secretion (see Barbeau \& Lillywhite, 2005; Gomez et al., 2006), while maintaining $T_{\mathrm{b}}$ above $T_{\mathrm{a}}$ which increases passive heat

82 loss, whilst reducing evaporative heat loss demands (Wygoda \& Williams, 1991). In contrast, evidence of an ecologically mediated pattern of SMR in ectotherms seems to be lacking since differences in SMR have largely been linked to differences in species activity patterns (Clarke \& 85 Johnston, 1999). 
86

87

88

89

90

91

92

93

Understanding the effect of temperature on key physiological traits in different anuran species (with different ecological specialisations) will enable us to better understand how changes in climate will affect this threatened vertebrate group (Pimm et al., 2014). They may also provide us with a snapshot of how physiological differences drive species-specific responses to climate change. Climate change is expected to be more pronounced in sub-Saharan Africa with increased drying, particularly in the winter rainfall region and less variable rainfall regimen across the region (Giannini et al., 2008; Engelbrecht, Engelbrecht \& Dyson, 2013), further placing amphibians of this region at high risk of extinction (Hof et al., 2011; Foden et al., 2013; Garcia et al., 2014; Mokhatla et al., 2015). Southern Africa has a diverse anuran fauna occupying many different habitat types (Alexander et al., 2004), and we may expect variation in the way each species will respond to environmental challenges in their respective environments (Loveridge, 1976).

In this study, we determine how ambient temperature affects $T_{\mathrm{b}}$, EWL and SMR of three different temperate African anuran species: the principally aquatic African clawed frog (Xenopus laevis), ii) stream-breeding common river frog (Amietia delalandii), and iii) principally terrestrial raucous toad (Sclerophrys capensis). We tested how the variation in $T_{\mathrm{a}}$ affects $T_{\mathrm{b}}$, whole-animal EWL and SMR in these three anuran species. We expect that differences in species' response are associated with differences in ecological specialisation. Specifically, we expect aquatic species to show higher EWL compared to terrestrial and semi-aquatic species, as conditions are buffered in aquatic environments (excluding biotic interactions), which may lead to reduced potential for evolutionary adaptation (Toledo \& Jared, 1993). Because of the negative relationship between water loss and activity patters (e.g., Peterman \& Semlitsch, 2014), we hypothesise that terrestrialadapted species would show reduced metabolic and water loss rates as an adaptation to terrestrial life (e.g., Wygoda, 1984). Likewise, species with intermediate life-histories (closely associated 
109 with water but not living in it), would exhibit an intermediary status. We expected that all species

110 will maintain $T_{\mathrm{b}}$ closer to $T_{\mathrm{a}}$, except at higher $T_{\mathrm{a}}$, where frogs were using evaporative cooling.

112 Methods

113 Study species

114 We chose three sympatric anuran species with different habitat specialisations, based on their

115 modes of egg deposition and development (Mercurio et al., 2009). The pipid, Xenopus laevis,

116 inhabits and breeds in permanent water bodies. This species is usually referred to as permanently

117 aquatic because it possesses several key physiological adaptations (e.g., lateral line system,

118 webbed hind legs etc.), suitable for an aquatic life style (see Measey, 2004). However, evidence

119 also suggests that under severe drying conditions of permanent ponds, $X$. laevis frequently disperse

120 overland (Measey, 2016). Amietia delalandii (family: Pyxicephalidae - previously known as $A$.

121 angolensis and $A$. quecketti) breeds in and inhabits streams and flowing rivers. Adults are usually

122 encountered on the water edge and on rocks along streams but are seldom encountered away from

123 water bodies (Channing, 2004). Sclerophrys capensis (previously known as Bufo rangeri and later

124 Amietophrynus rangeri) is a member of the toad family Bufonidae. These toads generally breed in

125 shallow, temporary water bodies and adult toads are adapted to a terrestrial mode of life

126 (Cunningham, 2004).

127 Adult individuals of our three target species were caught around the area of Port Elizabeth,

128 South Africa (Table 1). Experiments were undertaken under the animal research ethics clearance

129 permit number A13-SCI-ZOO-007 issued by the Research Ethics Committee (Animal) at the

130 Nelson Mandela University. Animals were collected under permit number CRO41/14CR, issued 
131 by the Department of Economic Development, Environmental Affairs and Tourism, Eastern Cape

132 Province. We caught between 20 and 30 individuals (of varying but overlapping interspecific body

133 size classes) excluding juveniles and gravid females. We attempted to maintain $M_{\mathrm{b}}$ comparable

134 among species as much as possible, although we found this difficult for $A$. delalandii. We included

135 both male and female individuals to account for variation that might be a result of sexual

136 dimorphism. Sexual dimorphism is particularly pronounced in anurans, with females generally

137 larger than males (see Table 1 for mass differences, with $X$. laevis showing the largest differences

138 between males and females). Animals were kept for a maximum period of 2-4 months in the lab

139 under environmentally enriched conditions (see below), until all experiments were completed.

140 After completing the experiments, animals were returned to their respective sites of capture.

141 Amietia delalandii were maintained in $110 \mathrm{~L}$ plastic boxes, with sand and small logs for cover,

142 at low densities (5 individuals per box). Sclerophrys capensis were kept in terraria made from

143 paddling pools $(d x h: 2.16 \mathrm{~m} \times 0.45 \mathrm{~m})$ with sand, water and small logs and bark to provide cover.

144 Xenopus laevis were kept in a freshwater tank $(l \times b \times h: 3.55 \mathrm{~m} \times 0.9 \mathrm{~m} \times 0.63 \mathrm{~m})$ with stacked-

145 bricks and stones to provide adequate cover and fed a diet of ox-heart. Both $A$. delalandii and $S$.

146 capensis were fed mealworms and crickets, dusted with calcium (ReptiCalcium, Zoo Med

147 Laboratories Inc; South Africa). All species had food available ad libitum, and the holding rooms

148 were maintained at $20^{\circ} \mathrm{C}$, on a $12: 12$ photoperiod. Atmospheric air was circulated to maintain a

149 constant temperature in the holding rooms, thus ambient humidity levels fluctuated with outside

150 air. Following Hillman et al. (2009), feeding of individuals ceased three days prior to experiments

151 to ensure that individuals were post-absorptive during experimental sessions. Water was provided

152 throughout the duration of the study (including periods when food was withheld) to prevent

153 dehydration stress. We further ensured that the terraria in which we held $S$. capensis and $A$. 
154 delalandii, were sprayed with water every 3 days to dampen the sand and we provided a bowl with

155 water daily where amphibians could rehydrate. Mass was recorded to the nearest $\pm 0.01 \mathrm{~g}$ before

156 and after each experimental run.

158 Gas exchange measurements

159 Standard metabolic rates and evaporative water loss measurements were conducted on the three 160 anuran species following Lighton (2008) and Steyermark et al., (2005), also see Gomes et al., 161 (2004) for a range of respirometry methods used, particularly for ectotherms. We used an open162 flow respirometry system operated on a push through mechanism on post-absorptive, non163 reproductive individuals, at rest (Sinclair et al., 2013). Experiments were conducted at 164 temperatures ranging from $5^{\circ} \mathrm{C}$ to $35^{\circ} \mathrm{C}$ at $5^{\circ} \mathrm{C}$ intervals (Dunlap, 1971). The order of experimental 165 temperatures runs was randomised to reduce the effects of experimental acclimation to any 166 directional shift in temperature. Eight individuals of each species ( 4 males: 4 females) were 167 randomly selected for trials at each temperature and a single trial was conducted on each individual 168 per temperature.

169 Prior to each experimental session, we recorded $T_{\mathrm{b}}$ (using a Fluke 80PK-1 probe, Type K 170 thermocouple -40 to $260^{\circ} \mathrm{C}$, to the nearest $0.1^{\circ} \mathrm{C}$ ), then patted frogs dry to remove excess water 171 from the skin and we then recorded $M_{\mathrm{b}}$ to the nearest $0.01 \mathrm{~g}$. All experiments were conducted 172 between $07 \mathrm{~h} 00$ and $18 \mathrm{~h} 00$, always within the light cycle of the 12:12 photoperiod, when animals 173 were less likely to be active (Gomes et al., 2004). Frogs were placed individually in suitably-sized 174 air tight glass metabolic chambers of three sizes: $341 \mathrm{ml}$ for small-, $476 \mathrm{ml}$ for medium and 978 $175 \mathrm{ml}$ for large frogs, depending on the size of the individual. A similar approach was followed by 
176 Young et al., (2005) in order to minimise large amounts of unoccupied spaces inside the metabolic

177 chamber (see also Gatten, 1987; Gomes et al., 2004). We found that individual frogs were agitated

178 when they experienced respirometry procedures for the first time. Prior to the respirometry

179 experiments, we performed a training session on each individual frog by placing them inside 180 metabolic chambers for 15 minutes at $20^{\circ} \mathrm{C}$. Frogs were noticeably quiescent during subsequent 181 respirometry runs.

A $0.5 \mathrm{~cm}$ layer of mineral oil was added to each chamber to prevent evaporation of excreted materials. Inside the chamber, a frog was placed on a plastic mesh platform (with sufficiently large holes for faeces to fall through), suspended at least $2 \mathrm{~cm}$ above the oil layer (Smit \& McKechnie, 2010). Air temperatures inside the metabolic chamber were recorded using a thermocouple probe (Fluke 54IIB, Fluke Corporation, Washington) that was inserted inside the chamber. Once the animal was placed in the chamber, we used "cling-wrap" (GLAD, South Africa) before sealing with a glass lid. After placing the lid, we placed Prestik, "Blu-Tac" type material (Bostik, Cape Town) around the lid of the metabolic chamber to minimise air leaks. Two metabolic chambers, one containing an animal, and the other an empty reference chamber (serving as a chamber to determine baseline levels) were placed in a custom-made environmental chamber made from a $100 \mathrm{~L}$ cooler box with the interior lined with copper tubing. Baseline levels were recorded for 30 minutes before each trial (Smit \& McKechnie, 2010; van de Ven et al., 2013). The temperature inside the cooler box was controlled by pumping temperature-controlled water through the copper tubing using a circulating water bath (FRB22D, Lasec, Cape Town, South Africa; see van de Ven, Mzilikazi \& McKechnie, 2013). A small fan was used to ensure air circulation inside the environmental chamber. 

Systems, Las Vegas, NV) to pump atmospheric air scrubbed of water vapour (using a Drierite column (98 \% $\mathrm{CaSO}_{4}, 2 \% \mathrm{CoCl}_{2}$, Sigma-Aldrich, South Africa) at a flow-rates of 100 to 600 mL.min ${ }^{-1}$, through the metabolic chambers. We calibrated the MFS-2 pumps using a flow-bubble meter (calibrated flow-rates were used in subsequent equations, see below). We scrubbed the air of water vapour to have better control of ambient humidity levels in the respirometry chamber (actual vapour pressures recorded for atmospheric air in Port Elizabeth varied greatly among days during our study period). Air from the metabolic chambers was sequentially sub-sampled, using Subsampler (SS3, Sable Systems, Las Vegas, NV) and a Multiplexer (V3, Sable Systems) was programmed though Expedata (Sable Systems, Las Vegas, NV) to record gas concentrations for each chamber at 20-minute intervals, recording an air sample every second. Subsampled air was first pulled through a water vapour analyser (RH-300, Sable Systems, Las Vegas, NV) to measure water vapour pressure. We were mainly interested in measuring total EWL, not different components of water loss such as boundary layer and cutaneous resistance; hence we did not use agar models in our approach (Buttemer, 1990). Air samples then passed through a carbon dioxide analyser (Ca-10a, Sable Systems, Las Vegas, NV) and finally through to an oxygen analyser (Fcusing live video feed for the duration of the trial. The thermocouple probe was used to measure

$216 \mathrm{~T}_{\text {air }}$ (air temperature inside the metabolic chamber). During a trial, frogs experienced one

217 controlled temperature at a time. A trial was considered completed when the water vapour pressure and temperature trace was stable for 20 minutes or if the animal appeared too distressed to continue with measurements. Although we acknowledge that different sized frogs show differences in cooling rates (Wygoda, 1988b; Wygoda, 1989), we assume that the final 20 minute interval of 
221 stable vapour pressure and temperature trace suggest that at this point, each individuals' $T_{\mathrm{b}}$

222 (irrespective of size) had reached equilibrium with the desired test temperature. Trials did not last

223 longer than 2 hours (following Dunlap, 1971). After each trial, we removed the frog from the

224 chamber, recorded cloacal temperature $\left(T_{\mathrm{b}}\right)$ within $30 \mathrm{~s}$ of removal (using a Fluke $80 \mathrm{PK}-1$ probe,

225 Type $\mathrm{K}$ thermocouple -40 to $260^{\circ} \mathrm{C}$ ) and the final $M_{\mathrm{b}}$. Species lost on average between three and

226 five percent of their initial $M_{\mathrm{b}}$ (see Table 1). This loss in $M_{\mathrm{b}}$ was comparable to other studies

227 looking water loss and metabolic rates in anurans (see Steyermark et al., 2005). In this study, it

228 was concluded that the average loss of 5\% in $M_{\mathrm{b}}$ suggested that the animals remained adequately

229 hydrated throughout the experimental trial (Steyermark et al., 2005). After each trial, frogs were

230 individually placed in temporary holding facilities. Xenopus laevis were kept in 20 L buckets, half-

231 filled with water at $20^{\circ} \mathrm{C}$ and fed ox heart. Both $S$. capensis and A. delalandii were kept in $0.5 \mathrm{~L}$

232 plastic container lined with a wet lab paper and were fed mealworms and crickets, respectively.

233 After each trial, individuals were eligible for selection for another trial run only after 3 days.

\section{Data extraction}

236 Once all experiments were complete, we used Expedata software to extract oxygen, carbon dioxide and water vapour pressure traces from data files. We selected the most stable 20 minutes trace in each run, when the animal was at rest. Standard metabolic rates can either be calculated using the rate of oxygen consumption or carbon dioxide production rates (Gatten et al., 1992; Lighton, 2008; Withers, 2001). We used rates of oxygen consumption $\left(\mathrm{VO}_{2}\right)$ at each temperature following Gomes et al., (2004). Moreover, flow rate was calibrated using a flow-bubble meter. To determine the rates of EWL, we converted rates of water vapour pressure (WVP) to water vapour density, which we subsequently converted to rates of EWL (see Lighton, 2008). Lastly, we calculated saturation 
244 WVP at each test temperature to determine vapour pressure deficit (VPD) as recent evidence 245 suggests that VPD directly drives rates of EWL in amphibians (e.g., Riddell \& Sears, 2015). We 246 calculated VPD by estimating the saturation vapour pressure at each air temperature we studied

247 from using the equations in Campbell \& Norman, (1998). We converted the absolute water vapour 248 pressure in the animal chamber to $\mathrm{kPa}$ and calculated the vapour pressure deficit as the difference 249 between saturation vapour pressure and absolute water vapour pressure. However, our 250 experimental design did not allow us to test for VPD directly (e.g., scrubbing water from incurrent air) but we tested if VPD was a better predictor of EWL in our test species (see Supplementary Table S1). We found that VPD was a better predictor of EWL in both A. delalandii and S. capensis 253 but not in $X$. laevis.

Statistical analysis

256 To determine the effect of $T_{\mathrm{a}}$ on $T_{\mathrm{b}}$, EWL and SMR of anurans, we used linear mixed-effect models 257 with the R package 'nlme' (Pinheiro et al., 2014) due to repeated measurements on individuals. We also included $M_{\mathrm{b}}$ and sex as fixed effects in models. Within ectotherm, $T_{\mathrm{b}}$ is highly correlated to $T_{\mathrm{a}}$ and we thus ran a repeated measures correlation using the R package "rmcorr" (Bakdash \& Marusich, 2017a; Bakdash \& Marusich, 2017b). We found a strong, significant positive correlation between $T_{\mathrm{a}}$ and $T_{\mathrm{b}}\left(r_{(96)}=0.9917 ; 95 \%\right.$ CI $\left.(0.988,0.994), P<0.001\right)$ for all three species (see

Figure 1). We included sex in the model because of the pronounced sexual dimorphism in anurans.

263 Furthermore, we wanted to determine if species differed in their responses to changes in $T_{\mathrm{a}}$. 264 However, this analysis was restricted to species with comparable $M_{\mathrm{b}}$ (i.e., $S$. capensis and $X$. laevis), because it is known to be a significant contributor to observed physiological difference.

266 We also ran repeated measure correlation between flow rate and EWL to determine if the variation 
267 in flow rate had any effect on EWL. We found a non-significant relationship $\left(r_{(97)}=0.157,95 \%\right.$

268 CI $(-0.044,0.345), P=0.122)$ between the two variables and thus did not include flow rate as a

269 fixed variable in subsequent models. We also determined the proportion of the variance explained

270 by the model (coefficient of determination $\mathrm{R}^{2}$ for mixed models following a procedure by

271 Nakagawa \& Schielzeth (2013) and Nakagawa, Johnson \& Schielzeth (2017). Furthermore, we

272 also determined the relative importance of each of the fixed variables in the model using the semi-

273 partial $\mathrm{R}^{2}$ as a measure of effect size (see Jaeger et al., 2017) using the 'r2glmm' package,

274 implemented in R (Jeager, 2017). All analysis were undertaken in R (R Development Core Team 275 2017).

276

277

Results

278

African clawed frog: Xenopus laevis

279

We found that $T_{\mathrm{b}}$ increased with an increase in $T_{\mathrm{a}}\left(F_{(6,23)} 1050.629 ; P<0.0001\right)$, although it did not affect $\operatorname{sex}\left(F_{(1,23)} 3.440 ; P=0.0765\right)$ and $M_{\mathrm{b}}\left(F_{(1,23)} 0.238 ; P=0.631\right.$; see Supplementary

Table S2 for semi-partial $R^{2}$ values). Whole-animal EWL increased at high $T_{\mathrm{a}}\left(F_{(1,22)}=16.201 ; P\right.$ $<0.0001$; see also Supplementary Table S2 for semi-partial $R^{2}$ values on the different temperature levels). We did not find any significant effect of EWL on sex $\left(F_{(1,23)} 3.056 ; P=0.094\right)$ and $M_{\mathrm{b}}(F$

$(1,23) 0.198 ; P=0.661)$. Furthermore, we found that whole-animal SMR increased with an increase 285 in $T_{\mathrm{a}}\left(F_{(6,23)}=10.659 ; P<0.0001\right)$, although we did not find any significant difference among 286 $\operatorname{sex}\left(F_{(1,23)} 3.354 ; P=0.080\right)$ and $M_{\mathrm{b}}\left(F_{(1,23)} 0.007 ; P=0.934\right)$. 
288 We found that $T_{\mathrm{b}}$ increased with an increase in $T_{\mathrm{a}}\left(F_{(6,24)}=1374.112 ; P<0.0001\right)$. Furthermore, $289 M_{\mathrm{b}}$ had a significant positive effect on $T_{\mathrm{b}}\left(F_{(1,24)}=8.196 ; P<0.01\right.$; semi-partial $\left.R^{2}=0.160\right)$, such 290 that $T_{\mathrm{b}}$ matched $T_{\mathrm{a}}$ closer in larger individuals while smaller individuals maintained $T_{\mathrm{b}}$ below $T_{\mathrm{a}}$. 291 However, we did not find a significant effect of $\operatorname{sex}\left(F_{(1,24)}=0.748 ; P=0.396\right)$ on $T_{\mathrm{b}}$. Whole292 animal EWL $\left(F_{(6,24)}=6.612 ; P<0.001\right.$, Figure 2$)$ and $\operatorname{SMR}\left(F_{(6,24)}=5.711 ; P<0.0001\right.$; Figure 293 3) increased with an increase in $T_{\mathrm{a}}$. We did not find a significant effect of $M_{\mathrm{b}}$ in both whole-animal $294 \operatorname{EWL}\left(F_{(1,24)}=1.341 ; P=0.258\right)$ and whole-animal SMR $\left(F_{(1,24)}=2.372 ; P=0.137\right)$, respectively 295 (see also Supplementary Table S3). Moreover, sex did not influence whole-animal EWL $\left(F_{(1,24)}=\right.$ 296 $0.205 ; P=0.655)$ and $\operatorname{SMR}\left(F_{(1,24)}=0.497 ; P=0.490\right)$.

Raucous toad: Sclerophrys capensis

Sclerophrys capensis $T_{\mathrm{b}}$ was positively correlated with $T_{\mathrm{a}}\left(F_{(1,28)}=420.726 ; P<0.0001\right.$; Figure 1). We also found that $M_{\mathrm{b}}$ had a significant positive effect on $T_{\mathrm{b}}\left(F_{(1,28)}=6.045 ; P<0.05\right.$, semipartial $\left.R^{2}=0.099\right)$ such that $T_{\mathrm{b}}$ matched $T_{\mathrm{a}}$ in larger individuals while smaller individuals generally maintained $T_{\mathrm{b}}$ below $T_{\mathrm{a}}$, although sex did not have an effect on $T_{\mathrm{b}}\left(F_{(1,19)}=0.020 ; P=0.890\right.$, semipartial $\left.R^{2}=0.036\right)$. Furthermore, we found that an increase in $T_{\mathrm{a}}$ lead to a significant increase in whole-animal EWL $\left(F_{(6,28)}=15.055 ; P<0.0001\right.$; Figure 3$)$, although $M_{\mathrm{b}}\left(F_{(1,28)}=3.708 ; P=\right.$ $0.064)$ and $\operatorname{sex}\left(F_{(1,19)}=1.190 ; P=0.289\right)$ did influence whole-animal EWL (see Supplementary Table S4 for semi-partial $\left.R^{2}\right)$. Whole-animal SMR also increased at high $T_{\mathrm{a}}\left(F_{(6,28)}=11.639 ; P<\right.$ 0.0001; Figure 3). In addition, we found that $M_{\mathrm{b}}$ had a positive significant effect on whole-animal

$308 \operatorname{SMR}\left(F_{(1,28)}=5.184 ; P<0.05\right.$, semi-partial $\left.R^{2}=0.086\right)$, although we found a non-significant sex 309 $\operatorname{effect}\left(F_{(1,19)}=0.228 ; P=0.638\right)$. 


\section{Discussion}

312 One of the greatest challenges in amphibians is that both metabolism and thermoregulation are not 313 only coupled, but also controlled by external factors such as environmental temperature. Thus, our

314 study aimed to assess how the variation in $T_{\mathrm{a}}$ affects key physiological traits in three different

315 African anuran species with different ecologies. We found that $T_{\mathrm{a}}$ had a significant positive effect 316 on $T_{\mathrm{b}}$, whole-animal EWL and whole-animal SMR for all species, irrespective of their ecological 317 niche. Secondly, we found that $M_{\mathrm{b}}$ influenced $T_{\mathrm{b}}$, in $A$. delalandii and $S$. capensis but not in $X$. 318 laevis. Furthermore, $M_{\mathrm{b}}$ did not influence rates of whole-animal EWL in all three species, but we 319 found that whole-animal SMR increased with an increase in $M_{\mathrm{b}}$ only for $S$. capensis. Lastly, we 320 did not find any difference between the sexes in $T_{\mathrm{b}}, \mathrm{EWL}, \mathrm{SMR}$.

\section{Body temperature}

323 The concept of thermal inertia suggests that although larger individuals take longer to warm up, they also take longer to cool down (Carey, 1978). A study looking at how $M_{\mathrm{b}}$ affects $T_{\mathrm{b}}$ in different toad species concluded that larger individuals had higher thermal inertia than small sized individuals (Carey, 1978). In addition, Newman \& Dunham (1994) found that Scaphiopus couchii toadlets that metamorphosed at larger sizes took longer to reach critical dehydration levels compared to small-sized toadlets. Collectively, these results highlight the importance of $M_{\mathrm{b}}$ as a significant factor influencing key physiological processes such as $T_{\mathrm{b}}$ through its effect on rates of heating and cooling (Wygoda, 1988a) particularly in vertebrate ectotherms. In this study, we found

331 that changes in $M_{\mathrm{b}}$ had a significant effect of $T_{\mathrm{b}}$ in $A$. delalandii and $S$. capensis. These results 
332 suggest that the effect of $M_{\mathrm{b}}$ on heat flux may be more beneficial for species spending a large 333 proportion of their time on land, where changes in temperature are more pronounced and may be 334 sudden.

Our results seem to suggest that although $M_{\mathrm{b}}$ is a key factor affecting $T_{\mathrm{b}}$ in amphibians, this may not be the case across a broad range of available environmental temperatures and species ecologies. Furthermore, we found no significant relationship between $M_{\mathrm{b}}$ and $T_{\mathrm{b}}$ in $X$. laevis despite the species showing the largest difference in sexual dimorphism (see Table 1). Wygoda (1988a) suggested that prolonged cooling may be adaptive as it assists anurans to maintain a higher $T_{\mathrm{b}}$ that is essential for performance under decreasing temperature conditions. Hence amphibians are expected to have larger body sizes in more temperate, cooler environments (Ashton, 2002) and with altitude (Measey \& van Dongen, 2006), although the generality of this assertion has been challenged, particularly in largely aquatic urodeles (Olalla-Tárraga \& Rodríguez, 2007) and in anurans (Gouveia et al., 2019).

We found that whole-animal EWL increased with an increase in $T_{\mathrm{a}}$ for all our species. We expected this result because amphibians use evaporative water loss to reduce heat gain, and water loss increases with an increase in metabolic rates (Hillman et al., 2009). Although our study was not designed to specifically test for the effect of VPD on EWL, we did show that $T_{\mathrm{a}}$ was strongly related to EWL while accounting for VPD, suggesting that elevations in EWL played a role in evaporative cooling in two of the three species considered (see Supplementary Table 1). We also wanted to determine whether different species differ in their ability to regulate water loss (e.g., 
354 Wygoda, 1984; Young et al., 2005). Both Wygoda (1984) and Young et al., (2005) concluded that 355 species that adopted an arboreal lifestyle show significantly reduced levels of water loss. In 356 addition to arboreal lifestyle, Tracy et al., (2010) concluded that both high cutaneous resistance to 357 water loss $\left(\mathrm{R}_{\mathrm{c}}\right)$, and larger $M_{\mathrm{b}}$ were important in reducing desiccation time in amphibians, although 358 high $\mathrm{R}_{\mathrm{c}}$ may not be beneficial to large-bodied frogs for thermoregulation (due to possibility of 359 overheating at high $T_{\mathrm{a}}$ ). In this study however, $M_{\mathrm{b}}$ and sex did not have an influence on rates of 360 whole-animal EWL in the three-species considered. While studying the relationship between

361 362 desiccation tolerance and body size, Schmid (1965), found no relationship between the two variables despite suggestion that small sized frogs' loose water more readily as compared to larger ones (Heatwole et al., 1969). Furthermore, there seems to be a difference in the onset of evaporative cooling such that species with high $\mathrm{R}_{\mathrm{c}}$ or atypical frog species only employing EWL at high ambient temperatures compared low and moderate $\mathrm{R}_{\mathrm{c}}$ or typical frogs (Tracy et al., 2008). Species with high $\mathrm{R}_{\mathrm{c}}$ are reported to have reduced EWL and have been observed to increase their $T_{\mathrm{b}}$ above ambient as an adaptation to terrestrial habitats (Buttemer, 1990; Tracy \& Christian, 2005). Tracy and Christian (2005) concluded that species with low EWL had low variance in $T_{\mathrm{b}}$ as a result of a negligible influence of evaporative cooling on thermoregulation, although this may not be beneficial, particularly at high $T_{\mathrm{a}}$ because reduced skin resistance at high $T_{\mathrm{a}}$ shortens desiccation time (Tracy et al., 2008). Coincidentally, species with the smallest variance in $T_{\mathrm{b}}$ were also some of the largest (see Tracy \& Christian, 2005). In the present study, we found that $S$. capensis had the smallest variance in $T_{\mathrm{b}}$ between $25^{\circ}$ and $35^{\circ} \mathrm{C}\left( \pm 4^{\circ} \mathrm{C}\right.$ as opposed to approximately $7^{\circ} \mathrm{C}$ for both A. delalandii and $X$. laevis; see Figure 1). Perhaps, maintaining small variations in $T_{\mathrm{b}}$ particularly at high $T_{\mathrm{a}}$ is beneficial for life on land. Despite $T_{\mathrm{b}}$ and $T_{\mathrm{a}}$ being strongly correlated, we found that $T_{\mathrm{b}}$ was typically slightly lower than $T_{\mathrm{a}}$ for all our species $\left(4-7^{\circ} \mathrm{C}\right.$ below $T_{\mathrm{a}}$, depending on the 
377 species), particularly at high $T_{\mathrm{a}}$ suggesting that all species were using evaporative cooling at high

$378 T_{\mathrm{a}}$. Indeed, while studying toads, Tracy (1978) postulated that toads possess an ability to withstand

379 higher $T_{\mathrm{b}}$ for longer periods, provided that the skin remains moist. Although the ability to use

380 evaporative cooling while managing water loss is important for amphibians, other factors such as

381 the ability to rehydrate quickly and absorb water from a variety of substrates (e.g. burrowing

382 species) may have been as important for amphibians to occupy such a variety of terrestrial habitats

383 through the course of evolution (Cartledge et al., 2006; Prates \& Navas, 2009), as well as being of

384 significance to current invasions (e.g. Vimercati et al., 2018).

385

386

387

388

389

390

391

392

393

394

395

396

397

398

\section{Standard metabolic rates}

Whole-animal SMR increases with an increase in $T_{\mathrm{a}}$ as a result of the increase in kinetic energy and reaction rate required at high temperatures (Brown et al., 2004; Clarke, 2006; Gillooly et al. 2001). We expected S. capensis to have comparatively low rates of SMR (particularly at high $T_{\mathrm{a}}$ ), as an adaptation to terrestrial life because: i) actively searching for food (insect prey) is coupled with water loss in terrestrial habitats and terrestrial specialists should adopt a sit-and weight foraging strategy, although see Pough \& Tiagen (1990), or ii) only be active nocturnally or at low to intermediate levels of $T_{\mathrm{a}}$ to reduce rates of EWL (Peterman \& Semlitsch, 2014). Indeed, we found that $S$. capensis had significantly lower rates of metabolism at $15^{\circ}, 25^{\circ}$ and $35^{\circ} \mathrm{C}$. Furthermore, we found whole-animal SMR increased with an increase in $M_{\mathrm{b}}$ only in $S$. capensis. During species comparisons, we also found that increases in $M_{\mathrm{b}}$ led to an increase in whole-animal EWL and SMR only at the highest tested $T_{\mathrm{a}}\left(35^{\circ} \mathrm{C}\right)$. This result is particularly interesting, suggesting that in Africa's temperate south, large bodies confer an advantage in delaying warming rates. 
Evidence on the influence of ecology on SMR has not been clearly articulated in the literature

400

401

402

403

404

405

406

407

408

409

410

411

412

413

414

415

416

417

418

419

420

421

as it may have been for EWL. Where there has been support, this has largely focused on comparing cold adapted and warm adapted species (e.g., Clark \& Johnston, 1999; Addo-Bediako, Chown \& Gaston, 2002). While looking at insects at a global scale, Addo-Bediako, Chown \& Gaston, (2002) found support for the metabolic cold adaptation hypothesis. Furthermore, Reinhold (1999) found that flying and highly vocal insect species had significantly high SMR than non-flying and less vocal insect species, respectively (but see also Hodkinson 2003). However, Clark \& Johnston (1999) did not find evidence to support the hypothesis on teleost fish. While studying different but closely related anuran species, Navas (1996) found that high elevations species had both high metabolic rates and aerobic scope compared to their low elevation congeners. Lastly, Navas (1997) concluded that several factors contribute differently to adaptations to cold environments in anurans such that changes in physiology may be more important for nocturnal and terrestrial frog species.

Ecological specialisations usually occur as a result of adaptation to a finite set of environments encountered (Navas, 1997; Poisot et al. 2011). Our results suggest that although variation in $T_{\mathrm{a}}$ is important in determining $T_{\mathrm{b}}$, EWL and SMR in amphibians, not all amphibians are affected in a similar fashion. Although $M_{\mathrm{b}}$ and sex (given the pronounced sexual dimorphism in anurans) have been identified as key factors affecting physiological traits in anurans, we suggest that perhaps this result should be considered in the context of each species' prevailing ecology and habitat specialisation with more emphasis on $M_{\mathrm{b}}$. However, certain caveats to this assertion need to be considered. First, we acknowledge that the observed differences could have been because the species that we considered represent very divergent groups (three different anuran families) so that the differences are a function of the divergent evolutionary history as opposed to different ecologies (but see Tracy \& Christian, 2005). Second, our set-up did not allow us to directly test 
422 for the relative importance of VPD on anurans, we did find that VPD was a better predictor of

423 EWL as opposed to $T_{\mathrm{b}}$ for two of the three species. Xenopus laevis is a fully aquatic species and

424 perhaps EWL may be somewhat independent of VPD over the test conditions we exposed the

425 animals to in our study, compared to more terrestrial species. Although we welcome these new

426 developments with VPD driving water loss rates in anurans, we also suggest that their generality

427 should be tested against species habitat specialisations.

428 Conclusions

429 We found that $T_{\mathrm{a}}$ has a significant influence on key physiological traits in the three temperate 430 African anuran species investigated such that it was, in most but not all, positively correlated with $431 T_{\mathrm{b}}$, whole-animal EWL and SMR. Secondly, in A. delalandii and S. capensis we found that at high 432 temperature EWL was mostly confounded by VPD, but not in $X$. laevis. We found that $M_{\mathrm{b}}$ 433 influenced $T_{\mathrm{b}}$ and whole-animal SMR in $S$. capensis and only $T_{\mathrm{b}}$ in $A$. delalandii. Lastly, $M_{\mathrm{b}}$ was 434 found not to impact rates of whole-animal EWL, irrespective of species ecological specialisation. 435 Our results suggest that the significance of $M_{\mathrm{b}}$ in influencing key physiological factors is not 436 universal (at least for EWL) and should also be looked at in the context of species ecology as $M_{\mathrm{b}}$ 437 did not influence $T_{\mathrm{b}}$, EWL and SMR in the principally aquatic $X$. laevis (see Olalla-Tárraga \& 438 Rodriguez, 2007; Gouveia et al., 2019). Understanding how species with different ecologies will 439 respond to climate change is particularly important in anurans where some species may respond 440 by altering their body sizes (e.g., Sheridan et al., 2018). Despite the pronounced sexual dimorphism 441 in anurans, sex did not influence the relationship of $T_{\mathrm{a}}$ with all physiological variables considered. 442 We suggest future studies should focus on disentangling the importance of $M_{\mathrm{b}}$ in large sample 443 sized, phylogenetically related, non-arboreal, anurans as information of how $T_{\mathrm{a}}$ affects key 444 physiological traits in these species is currently lacking. Furthermore, future work should be 
445 undertaken to understand energy demands of different species, such as stream breeding species,

446 given the threats that they currently face (Sodhi et al., 2008) particularly when considering the

447 expected effects of climate change on amphibians (Buckley et al., 2012; Deutsch et al., 2008). 


\section{Acknowledgements}

449 We would like to thank Ryan Rambaran, Magda Hawkins, Adrian Evans, Melissa Scerbo, 450 Stephanie Martins, Werner Conradie and Bryan Reeves for their help in the field. We would also 451 like to thank Sarah Davies and Giovanni Vimercati for fruitful discussions throughout the different 452 stages of this manuscript. We would also like to thank both reviewers for their constructive 453 comments that they provided. We firmly believe that their contributions have significantly 454 improved the quality of this manuscript. MMM \& JM are grateful to the DST-NRF Centre of 455 Excellence for Invasion Biology for their support. 
456

457

458

459

460

461

462

463

464

465

466

467

468

469

470

471

472

473

474

475

476

477

478

479

480

481

482

483

484

485

486

\section{References}

Addo-Bediako A, Chown SL, Gaston KJ. 2002. Metabolic cold adaptation in insects: a large-scale perspective. Functional Ecology 16:332-338.

Alexander G, Harrison J, Fairbanks D, Navarro R. 2004. Biogeography of the frogs of South Africa, Lesotho and Swaziland. In: Minter LR, Burger M, Harrison JA, Braack HH, Bishop PJ, Kloepfer D, eds. Atlas and red data book of the frogs of South Africa, Lesotho and Swaziland. SI/MAB Series \#9 ed. Washington, DC: Smithsonian Institute, 31-47

Angilletta MJ. 2001. Thermal and physiological constraints on energy assimilation in a widespread lizard (Sceloporus undulatus). Ecology 82:3044-3056.

Angilletta MJ, Niewiarowski PH, Navas CA. 2002. The evolution of thermal physiology in ectotherms. Journal of Thermal Biology 27:249-268.

Ashton KG. 2002. Do amphibians follow Bergmann's rule? Canadian Journal of Zoology 80:708-716.

Bakdash JZ, Marusich LR. 2017a. Repeated measures correlation. Frontiers in Psychology 8.

Bakdash JZ, Marusich LR. 2017b. Repeated Measures Correlation Package 'rmcorr'. 0.2.0 ed.

Barbeau TR, Lillywhite HB. 2005. Body wiping behaviors associated with cutaneous lipids in hylid tree frogs of Florida. Journal of Experimental Biology 208:2147-2156.

Brattstrom BH. 1979. Amphibian temperature regulation studies in the field and laboratory. American Zoologist 19:345-356.

Brown JH, Gillooly JF, Allen AP, Savage VM, West GB. 2004. Toward a metabolic theory of ecology. Ecology 85:1771-1789.

Buckley LB, Hurlbert AH, Jetz W. 2012. Broad-scale ecological implications of ectothermy and endothermy in changing environments. Global Ecology and Biogeography 21:873-885.

Buckley LB, Jetz W. 2007. Environmental and historical constraints on global patterns of amphibian richness. Proceedings of the Royal Society B: Biological Sciences 274:1167-1173. 10.1098/rspb.2006.0436.

Buttemer WA. 1990. Effect of temperature on evaporative water loss of the Australian tree frogs Litoria caerulea and Litoria chloris. Physiological Zoology 63:1043-1057.

Burggren WW, Vitalis TZ. 2005. The interplay of cutaneous water loss, gas exchange and blood flow in the toad, Bufo woodhousei: adaptations in a terrestrially adapted amphibian. Journal of Experimental Biology 208:105-112. 
487 Campbell GS, Norman, JM. 1998. An introduction to environmental biophysics. Springer$488 \quad$ Verlag, New York, New York, USA

489 Carey C. 1978. Factors affecting body temperatures of toads. Oecologia 35:197-219.

490 Cartledge V, Withers P, Thompson G, McMaster K. 2006. Water relations of the burrowing sandhill frog, Arenophryne rotunda (Myobatrachidae). Journal of Comparative Physiology B 176:295-302.

Channing A. 2004. Afrana angolensis. In: Minter LR, Burger M, Harrison JA, Braack HH, Bishop PJ, Kloepfer D, eds. Atlas and red data book of the frogs of South Africa, Lesotho and Swaziland. SI/MAB Series \#9 ed. Washington, DC: Smithsonian Institute, 270-271.

Chown SL, van Rensburg BJ, Gaston KJ, Rodrigues AS, van Jaarsveld AS. 2003. Energy, species richness, and human population size: conservation implications at a national scale. Ecological Applications 13:1233-1241.

Clarke A. 2006. Temperature and the metabolic theory of ecology. Functional Ecology 20:405-412.

Clarke A, Johnston NM. 1999. Scaling of metabolic rate with body mass and temperature in teleost fish. Journal of Animal Ecology 68:893-905.

Cunningham M. 2004. Bufo rangeri. In: Minter LR, Burger M, Harrison JA, Braack HH, Bishop PJ, Kloepfer D, eds. Atlas and red data book of the frogs of South Africa, Lesotho and Swaziland. SI/MAB Series \#9 ed. Washington, DC: Smithsonian Institution, 77-80.

Currie DJ. 1991. Energy and large-scale patterns of animal-and plant-species richness. American Naturalist 137:27-49.

Dabés L, Bonfim VMG, Napoli MF, Klein W. 2012. Water balance and spatial distribution of an anuran community from Brazil. Herpetologica 68:443-455.

Deutsch CA, Tewksbury JJ, Huey RB, Sheldon KS, Ghalambor CK, Haak DC, Martin PR. 2008. Impacts of climate warming on terrestrial ectotherms across latitude. Proceedings of the National Academy of Sciences 105:6668-6672.

Dohm MR, Mautz WJ, Looby PG, Gellert KS, Andrade JA. 2001. Effects of ozone on 515 evaporative water loss and thermoregulatory behavior of marine toads (Bufo marinus). Environmental Research 86:274-286. 
516

517

518

519

520

521

522

523

524

525

526

527

528

529

530

531

532

533

534

535

536

537

538

539

540

541

542

543

544

545

Dunlap DG. 1971. Acutely measured metabolic rate-temperature curves in the cricket frog, Acris crepitans. Comparative Biochemistry and Physiology Part A: Molecular \& Integrative Physiology 38:1-16.

Foden WB, Butchart SH, Stuart SN, Vie JC, Akcakaya HR, Angulo A, DeVantier LM, Gutsche A, Turak E, Cao L, Donner SD, Katariya V, Bernard R, Holland RA, Hughes AF, O'Hanlon SE, Garnett ST, Sekercioglu CH, Mace GM. 2013. Identifying the world's most climate change vulnerable species: a systematic trait-based assessment of all birds, amphibians and corals. PLoS ONE 8:e65427. 10.1371/journal.pone.0065427

Garcia RA, Araújo MB, Burgess ND, Foden WB, Gutsche A, Rahbek C, Cabeza M. 2014. Matching species traits to projected threats and opportunities from climate change. Journal of Biogeography 41:724-735.

Gatten RE. 1987. Activity metabolism of anuran amphibians: tolerance to dehydration. Physiological Zoology 60: 576-585.

Gatten R, Miller K, Full R. 1992. Energetics at rest and during locomotion. In: Feder ME, Burggren WW, eds. Environmental physiology of the amphibians. Chicago: The University of Chicago Press, 314-377.

Gillooly JF, Brown JH, West GB, Savage VM, Charnov EL. 2001. Effects of size and temperature on metabolic rate. Science 293:2248-2251.

Gomes FR, Chauí-Berlinck JG, Bicudo JEP, Navas CA. 2004. Intraspecific relationships between resting and activity metabolism in anuran amphibians: influence of ecology and behavior. Physiological and Biochemical Zoology 77:197-208.

Gomez NA, Acosta M, Zaidan III F, Lillywhite HB. 2006. Wiping behavior, skin resistance, and the metabolic response to dehydration in the arboreal frog Phyllomedusa hypochondrialis. Physiological and Biochemical Zoology 79:1058-1068.

Gouveia SF, Bovo RP, Rubalcaba JG, Da Silva FR, Maciel NM, Andrade DV, Martinez PA. 2019. Biophysical modeling of water economy can explain geographic gradient of body size in anurans. The American Naturalist 193:51-58.

Heatwole H, Torres F, de Austin SB, Heatwole A, 1969. Studies on anuran water balance-I. Dynamics of evaporative water loss by the coqui, Eleutherodactylus portoricensis. Comparative Biochemistry and Physiology 28: 245-269. 
546 Herrel A, Bonneaud C. 2012. Temperature dependence of locomotor performance in the tropical clawed frog, Xenopus tropicalis. Journal of Experimental Biology 215:2465-2470.

Herrel A, Vasilopoulou-Kampitsi M, Bonneaud C. 2014. Jumping performance in the highly aquatic frog, Xenopus tropicalis: sex-specific relationships between morphology and performance. PeerJ 2:e661.

Hillman SS, Withers PC, Drewes RC, Hillyard SD. 2009. Ecological and environmental physiology of amphibians: Oxford University Press New York.

Hodkinson, ID. 2003. Metabolic cold adaptation in arthropods: a smaller-scale perspective. Functional Ecology 17: 562-567.

Hof C, Araújo MB, Jetz W, Rahbek C. 2011. Additive threats from pathogens, climate and landuse change for global amphibian diversity. Nature 480:516-519.

Huey RB. 1991. Physiological Consequences of Habitat Selection. American Naturalist 137:S91-S115.

Huey RB, Kingsolver JG. 1989. Evolution of thermal sensitivity of ectotherm performance. Trends in Ecology \& Evolution 4:131-135.

Huey RB, Stevenson R. 1979. Integrating thermal physiology and ecology of ectotherms: a discussion of approaches. American Zoologist 19:357-366.

Jaeger BC. 2017. R Core Team (2017). r2glmm: R Square for mixed (multilevel) models. R package version 0.1.2. Available at http://CRAN R-project.org/package $=\mathrm{r} 2 \mathrm{glmm}$.

Jaeger BC, Edwards L.J. Das K. Sen PK. 2017. An R ${ }^{2}$ statistic for fixed effects in the generalized linear mixed model. Journal of Applied Statistics 44: 1086-1105.

Köhler A, Sadowska J, Olszewska J, Trzeciak P, Berger-Tal O, Tracy CR. 2011. Staying warm or moist? Operative temperature and thermal preferences of common frogs (Rana temporaria), and effects on locomotion. The Herpetological Journal 21:17-26.

Lighton JR. 2008. Measuring Metabolic Rates: A Manual for Scientists: Oxford University Press.

Lillywhite HB. 1970. Behavioral temperature regulation in the bullfrog, Rana catesbeiana. Copeia 1970:158-168.

Loveridge J. 1976. Strategies of water conservation in southern African frogs. Zoologica Africana 11:319-333.

McNab BK. 2002. The physiological ecology of vertebrates: a view from energetics: Cornell 576 University Press. 
577

Measey GJ. 2004. Xenopus laevis. In: Minter LR, Burger M, Harrison JA, Braack HH, Bishop PJ, Kloepfer D, eds. Atlas and red data book of the frogs of South Africa, Lesotho and Swaziland. SI/MAB Series \#9 ed. Washington, DC: Smithsonian Institution, 258-260.

Measey GJ. 2016. Overland movement in African clawed frogs (Xenopus laevis): a systematic review. PeerJ 4:e2474.

Measey GJ, van Dongen S. 2006. Bergmann's rule and the terrestrial caecilian Schistometopum thomense (Amphibia: Gymnophiona: Caeciliidae). Evolutionary Ecology Research 8: 1049-1059.

Mercurio V, Böhme W, Streit B. 2009. Reproductive diversity of Malawian anurans. Herpetology Notes 2:175-183.

Mokhatla MM, Rödder D, Measey GJ. 2015. Assessing the effects of climate change on distributions of Cape Floristic Region amphibians. South African Journal of Science 111:7 Pages.

Nakagawa S. Johnson PC, Schielzeth H. 2017. The coefficient of determination $\mathrm{R}^{2}$ and intraclass correlation coefficient from generalized linear mixed-effects models revisited and expanded. Journal of the Royal Society Interface 14: 20170213.

Nakagawa S, Schielzeth H. 2013. A general and simple method for obtaining $R^{2}$ from generalized linear mixed-effects models. Methods in Ecology and Evolution 4:133-142.

Navas CA. 1996. Metabolic physiology, locomotor performance, and thermal niche breadth in neotropical anurans. Physiological Zoology 69: 1481-1501.

Navas CA. 1997. Thermal extremes at high elevations in the Andes: physiological ecology of frogs. Journal of Thermal Biology 22: 467-477.

Newman R, Dunham A. 1994. Size at metamorphosis and water loss in a desert anuran (Scaphiopus couchii). Copeia 1994:372-381.

Olalla-Tárraga MÁ, Rodríguez MÁ. 2007. Energy and interspecific body size patterns of amphibian faunas in Europe and North America: anurans follow Bergmann's rule, urodeles its converse. Global Ecology and Biogeography 16:606-617. 10.1111/j.14668238.2007.00309.x

Peterman W, Semlitsch R. 2014. Spatial variation in water loss predicts terrestrial salamander distribution and population dynamics. Oecologia 176:357-369. 
607

Pimm SL, Jenkins CN, Abell R, Brooks TM, Gittleman JL, Joppa LN, Raven PH, Roberts CM, Sexton JO. 2014. The biodiversity of species and their rates of extinction, distribution, and protection. Science 344:1246752.

Pinheiro J, Bates D, DebRoy S, Sarkar D. 2014. R Core Team (2014) nlme: linear and nonlinear mixed effects models. R package version 3.1-117. Available at $h$ ttp://CRAN R-project org/package $=$ nlme.

Poisot T, Bever JD, Nemri A, Thrall PH, Hochberg ME. 2011. A conceptual framework for the evolution of ecological specialisation. Ecology Letters 14:841-851.

Pough FH, Taigen TL. 1990. Metabolic correlates of the foraging and social behaviour of dartpoison frogs. Animal Behaviour 39:145-155.

Prates I, Navas CA. 2009. Cutaneous resistance to evaporative water loss in Brazilian Rhinella (Anura: Bufonidae) from contrasting environments. Copeia 2009:618-622.

Qian H, Wang X, Wang S, Li Y. 2007. Environmental determinants of amphibian and reptile species richness in China. Ecography 30:471-482. DOI10.1111/j.2007.0906-7590.05025.x

R Development Core Team. 2017. R: A Language and Environment for Statistical Computing. R Version 3.4.2 ed. Vienna, Austria: R Foundation for Statistical Computing.

Riddell EA, Apanovitch EK, Odom JP, Sears MW. 2017. Physical calculations of resistance to water loss improve predictions of species range models. Ecological Monographs 87:21-33.

Riddell EA, Sears MW. 2015. Geographic variation of resistance to water loss within two species of lungless salamanders: implications for activity. Ecosphere 6:1-16.

Reinhold K, 1999. Energetically costly behaviour and the evolution of resting metabolic rate in insects. Functional Ecology 13:217-224.

Schmid WD. 1965. Some aspects of the water economies of nine species of amphibians. Ecology 46: $261-269$.

Seebacher F, Alford RA. 2002. Shelter microhabitats determine body temperature and dehydration rates of a terrestrial amphibian (Bufo marinus). Journal of Herpetology 36:69-75.

Seebacher F, Franklin CE. 2005. Physiological mechanisms of thermoregulation in reptiles: a review. Journal of Comparative Physiology B 175:533-541.

Sheridan JA, Caruso NM, Apodaca JJ, Rissler LJ. 2018. Shifts in frog size and phenology: testing predictions of climate change on a widespread anuran using data from prior to rapid climate warming. Ecology and Evolution 8:1316-1327. 
638 Shoemaker V, Nagy KA. 1977. Osmoregulation in amphibians and reptiles. Annual Review of Physiology 39:449-471.

Sinclair BJ, Stinziano JR, Williams CM, MacMillan HA, Marshall KE, Storey KB. 2013. Real-time measurement of metabolic rate during freezing and thawing of the wood frog, Rana sylvatica: implications for overwinter energy use. Journal of Experimental Biology 216:292-302.

Smit B, McKechnie AE. 2010. Avian seasonal metabolic variation in a subtropical desert: basal metabolic rates are lower in winter than in summer. Functional Ecology 24:330-339.

Sodhi NS, Bickford D, Diesmos AC, Lee TM, Koh LP, Brook BW, Sekercioglu CH, decline. PLOS ONE 3:e1636.

Spotila JR, Berman EN. 1976. Determination of skin resistance and the role of the skin in controlling water loss in amphibians and reptiles. Comparative Biochemistry and Physiology Part A: Physiology 55:407-411.

Steyermark AC, Miamen AG, Feghahati HS, Lewno AW. 2005. Physiological and morphological correlates of among-individual variation in standard metabolic rate in the leopard frog Rana pipiens. Journal of Experimental Biology 208:1201-1208.

Thorson TB. 1955. The relationship of water economy to terrestrialism in amphibians. Ecology 36:100-116.

Toledo R, Jared C. 1993. Cutaneous adaptations to water balance in amphibians. Comparative Biochemistry and Physiology Part A: Physiology 105:593-608.

Tracy CR, Betts G, Richard Tracy C, Christian KA. 2007. Plaster models to measure operative temperature and evaporative water loss of amphibians. Journal of Herpetology 41:597-603.

Tracy CR, Christian KA. 2005. Preferred temperature correlates with evaporative water loss in hylid frogs from northern Australia. Physiological and Biochemical Zoology 78:839-846.

Tracy CR, Christian KA, Betts G, Tracy CR. 2008. Body temperature and resistance to evaporative water loss in tropical Australian frogs. Comparative Biochemistry and Physiology Part A: Molecular \& Integrative Physiology 150:102-108.

Tracy CR, Christian KA, Tracy CR. 2010. Not just small, wet, and cold: effects of body size and skin resistance on thermoregulation and arboreality of frogs. Ecology 91:1477-1484. 
668 van de Ven TM, Mzilikazi N, McKechnie AE. 2013. Seasonal metabolic variation in two populations of an Afrotropical Euplectid bird. Physiological and Biochemical Zoology 86:19-26.

Wilson R, James R, Johnston I. 2000. Thermal acclimation of locomotor performance in tadpoles and adults of the aquatic frog Xenopus laevis. Journal of Comparative Physiology, B 170:117-124.

Withers P. 2001. Design, calibration and calculation for flow-through respirometry systems. Australian Journal of Zoology 49:445-461.

Wygoda ML. 1988a. Adaptive control of water loss resistance in an arboreal frog. Herpetologica 44:251-257.

Wygoda ML. 1988b. A comparative study of time constants of cooling in green tree frogs (Hyla cinerea) and southern leopard frogs (Rana sphenocephala). Herpetologica 44:261-265.

Wygoda ML. 1989. A comparative study of heating rates in arboreal and nonarboreal frogs. Journal of Herpetology 23:141-145.

Wygoda ML. 1984. Low cutaneous evaporative water loss in arboreal frogs. Physiological Zoology 57:329-337.

Wygoda ML, Garman RH. 1993. Ontogeny of resistance to water loss in green tree frogs, Hyla cinerea. Herpetologica 49:365-374.

Wygoda ML, Williams AA. 1991. Body temperature in free-ranging green tree frogs (Hyla cinerea): a comparison with "typical" frogs. Herpetologica 47: 328-335.

Young JE, Christian KA, Donnellan S, Tracy CR, Parry D. 2005. Comparative analysis of cutaneous evaporative water loss in frogs demonstrates correlation with ecological habits. Physiological and Biochemical Zoology 78:847-856.

Young JE, Tracy CR, Christian KA, McArthur LJ, Beaupre S. 2006. Rates of cutaneous evaporative water loss of native Fijian frogs. Copeia 2006:83-88. 


\section{Figure 1}

Increasing body temperature as a function of ambient temperature in African anurans Relationship between $T_{\mathrm{a}}$ and $T_{\mathrm{b}}$ of different functional groups over a range of different test ambient temperatures $\left(T_{\mathrm{a}}\right)$. The solid line indicates $Y=X$ relationship representing a typical 1:1 $T_{\mathrm{a}}$ vs $T_{\mathrm{b}}$ relationship depicting an amphibian incapable of regulating $T_{\mathrm{b}}$ through physiological or behavioural means, to highlight how $T_{\mathrm{b}}$ deviates from $T_{\mathrm{a}}$ particularly at low and high $T_{\mathrm{a}}$. 


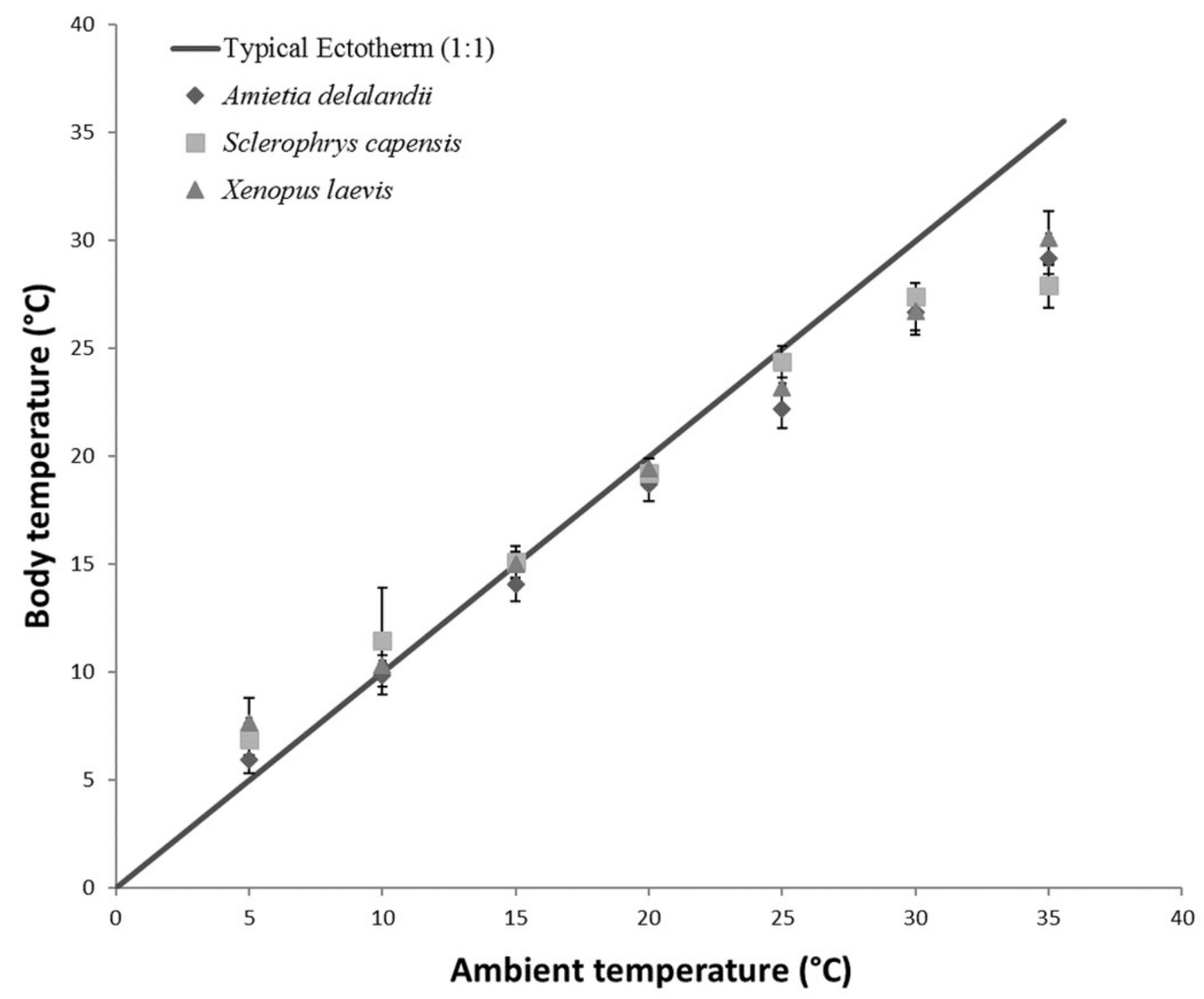




\section{Figure 2}

Increasing rates of evaporative water loss (EWL) as a function of temperature in african anurans

Data points represents the relationship between whole-animal EWL and body temperature ( $T$ b ) at each of the test temperatures. Vertical error bars represents the variation (Standard Error) in whole-animal EWL and the horizontal error bars represents the variation (Strandard error) in body temperature. 


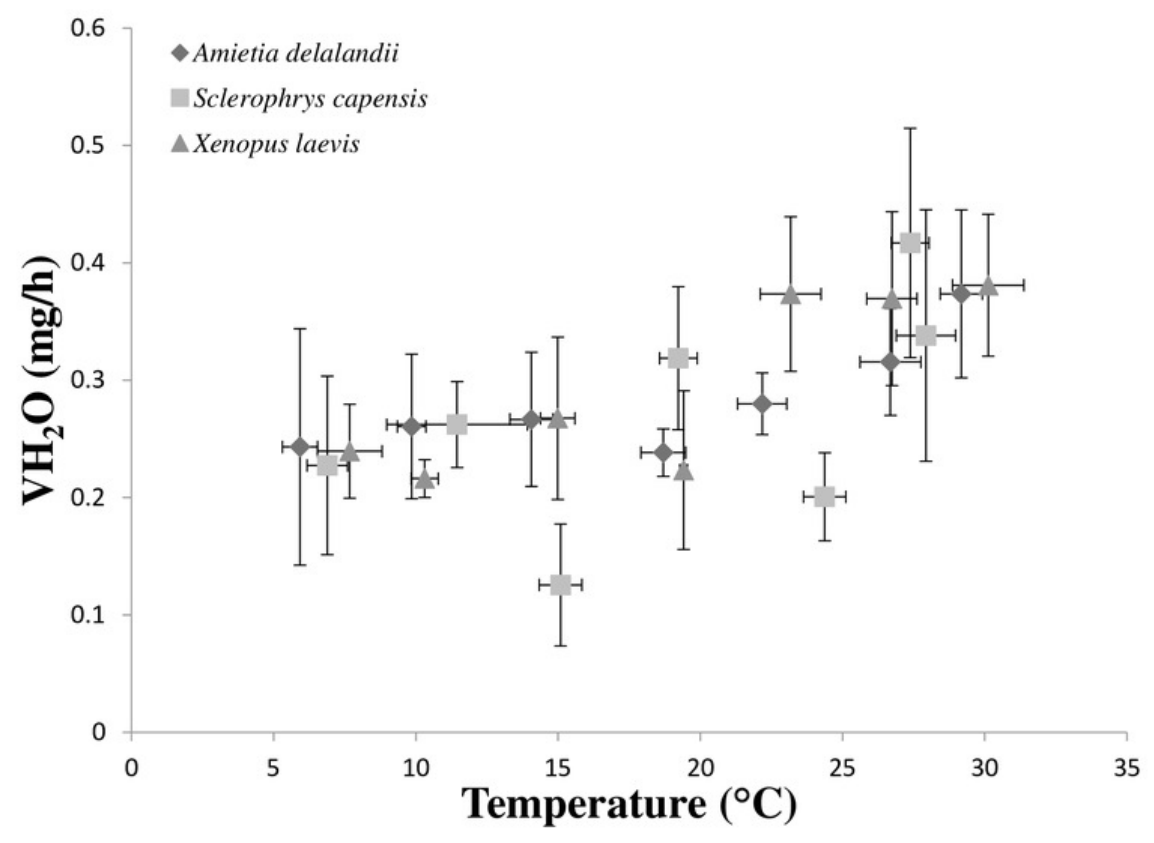




\section{Figure 3}

Increasing standsrd metabolic rates as a function of temperature in African anurans

Data points represents the relationship between whole-animal SMR and body temperature ( $T$ $b$ ) at each of the test temperatures. Vertical error bars represents the variation (Standard Error) in whole-animal Standard Metabilic Rates and the horizontal error bars represents the variation (Strandard error) in body temperature. 


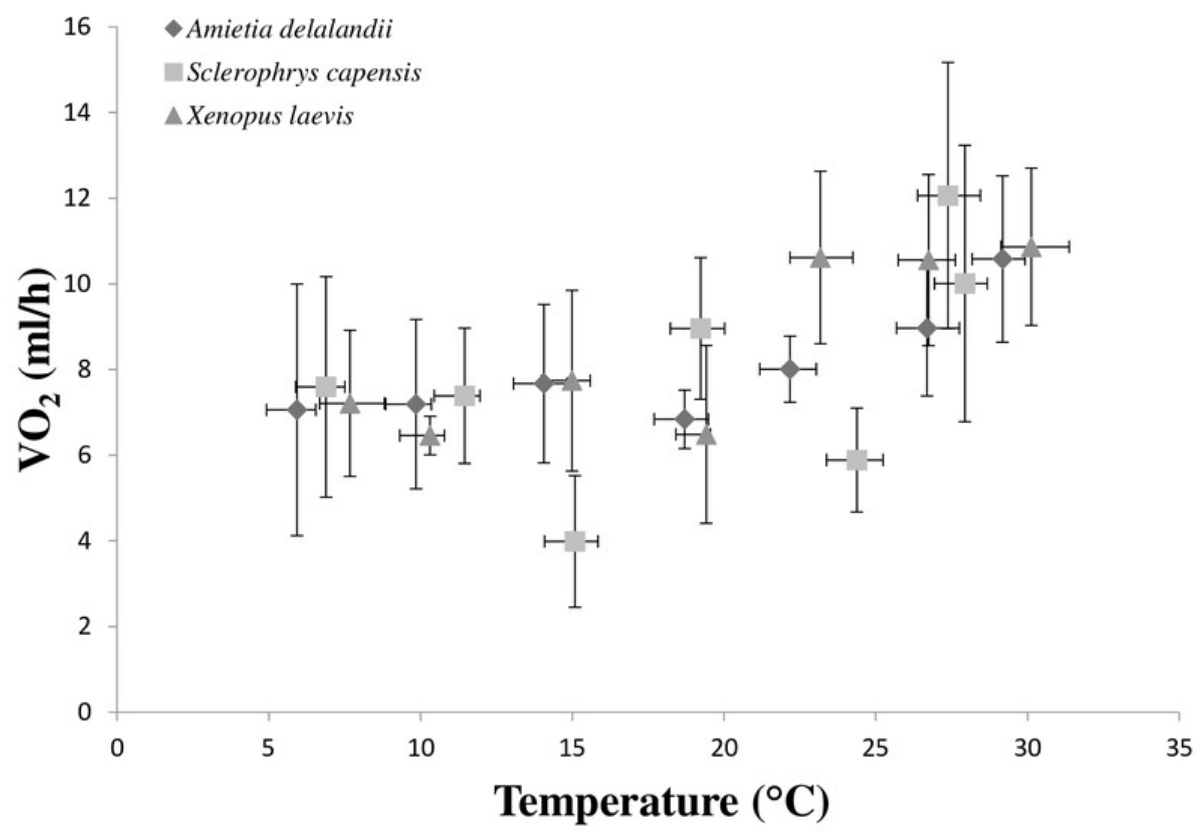




\section{Table 1 (on next page)}

Mean body sizes

Sample size, body mass $(\mathrm{g})$ (mean $\pm \mathrm{SD}$ ) and mean percentage body mass loss (mean $\pm \mathrm{SD}$ ) of individuals after two hours of each experimental trial. 


\section{$1 \quad$ Tables}

2 Table 1. Sample size, body mass $(\mathrm{g})($ mean $\pm \mathrm{SD})$ and mean percentage body mass loss (mean $\pm \mathrm{SD})$

3 of individuals after two hours of each experimental trial.

\begin{tabular}{|c|c|c|c|c|c|}
\hline & \multicolumn{2}{|r|}{ Male } & \multicolumn{2}{|r|}{ Female } & \\
\hline Species & $\mathbf{N}$ & Mass (g) & $\mathbf{N}$ & Mass (g) & $\% M_{\mathrm{b}}$ loss after $2 \mathrm{hr}$ \\
\hline Amietia delalandii & 15 & $7.65 \pm 1.61$ & 9 & $15.98 \pm 6.03$ & $5.2 \pm 2.85$ \\
\hline Sclerophrys capensis & 10 & $50.55 \pm 8.91$ & 14 & $82.58 \pm 26.26$ & $3.91 \pm 3.84$ \\
\hline Xenopus laevis & 11 & $29.87 \pm 10.52$ & 22 & $70.75 \pm 30.55$ & $3.21 \pm 1.66$ \\
\hline
\end{tabular}

4

5 